\title{
How Digital Economy Helps Rural Poverty Alleviation and Rural Revitalization in China
}

\author{
Xun Zhang ${ }^{1}$, Renfei Luo ${ }^{1, *}$, Ying Shi ${ }^{1}$ and Yanzhen Shangguan ${ }^{2}$ \\ ${ }^{1}$ Guangdong University of Finance \& Economics, International Business School, Innovation Center for China-US Youth Exchange, \\ Foshan, China \\ ${ }^{2}$ Tianhe District Taxation Bureau State Administration of Taxation, Guangzhou, China
}

\begin{abstract}
In the context of the implementation of the rural revitalization strategy, the development of the digital economy closely connects with it. The realization of rural revitalization needs to make full use of the advantages of the digital economy to promote the process of rural revitalization. The digital wave is a huge opportunity for the poor to bridge the gap between rich and poor, seize digital opportunities, share digital dividends, achieve sustainable poverty alleviation, and prevent intergenerational transmission of poverty. The article will focus on two aspects of rural e-commerce and mobile payment. Through the discussion of the aspects, this paper gives the suggestion to the government, platforms, enterprises and farmers to work together to promote agricultural development and realize industrial digitalization by using existing resources.
\end{abstract}

\section{Introduction}

In recent years, China's digital technology has penetrated widely into the fields of production and life and public governance, and the digital economy has been booming. In 2019, the added value of China's digital economy reached 35.8 trillion yuan, accounting for more than $1 / 3$ of GDP. Under the background of normalized epidemic prevention and control, digital technology will build a new industrial ecology and form a stronger innovation vitality. The digital economy will lead a new round of economic cycle and become a new engine of economic development.

\subsection{China's digital economy maintains a strong momentum of development}

China has the world's largest Internet population, with more than 900 million Internet users; it has the most active investment in the digital economy. China's ecommerce transaction scale has ranked first in the global e-commerce market for many years, and its mobile payment penetration rate has ranked first in the world. It has the most dynamic entrepreneurial ecosystem. On the list of 500 unicorn companies in the world released by the world-renowned data think tank CB Insights, there are 119 Chinese companies, ranking second.

\subsection{China's digital economy promotes the development of e-commerce}

In the development of digitization, digital technologies such as the Internet, cloud computing, big data, and artificial intelligence are creating new infrastructure systems for all styles of life. These changes will play a very important strategic role in the reshaping of the new business landscape in the future and the growth of corporate digital competitiveness. As a form of ecommerce that uses live broadcast as a channel to achieve marketing purposes, live e-commerce is also the background of the digital age. The product of the twoway integration of live broadcast and e-commerce.

In the process of China's transformation from traditional agriculture to modern digital agriculture, there will inevitably be a development bottleneck, so it is imperative to study a set of rural digital economy development countermeasures suitable for China's national conditions. This paper discuss the prominent problems in the current stage of agricultural digital transformation in China and put forward corresponding countermeasures to promote the development of rural revitalization empowered by digital economy.

\section{The development of China's digital economy in rural areas}

\subsection{The scale of China's rural e-commerce has increased steadily}

The "Digital White Paper" issued by the Ministry of Industry and Information Technology pointed out that the digital economy could divide into three stages: information digitization, business digitization, and digital transformation. In rural areas where the scale of nonnetizens is huge, compared with cities, the development of the digital economy is relatively lagging in terms of

\footnotetext{
* Corresponding author: RenfeiLuo@GDUFE.edu.cn 
information or business. However, in recent years, China's rural e-commerce has shown a momentum of development that cannot be underestimated.

With the penetration and development of e-commerce in counties, the systems of relevant policy support, standard setting, brand building, characteristic industry cultivation, and the upsurge of agricultural products were improved, and county e-commerce has gradually entered a stage of high-quality development. According to Oteou's monitoring data, in 2019, the nationwide county network retail sales reached 3,096.16 billion yuan, a year-on-year increase of $23.5 \%$.

According to the "Report on China's Rural Ecommerce Development (2019-2020)" released at the Fifth China Rural E-commerce Conference, the scale of China's rural e-commerce has risen steadily. In the first half of 2020, rural online retail will reach 766.85 billion yuan, accounting for $14.9 \%$ of the national online retail, retail sales increased by $5.0 \%$ over the same period last year. Among them, the national online retail sales of agricultural products reached 193.77 billion yuan, a yearon-year increase of $39.7 \%$, accounting for $4.6 \%$ of the national online retail sales.

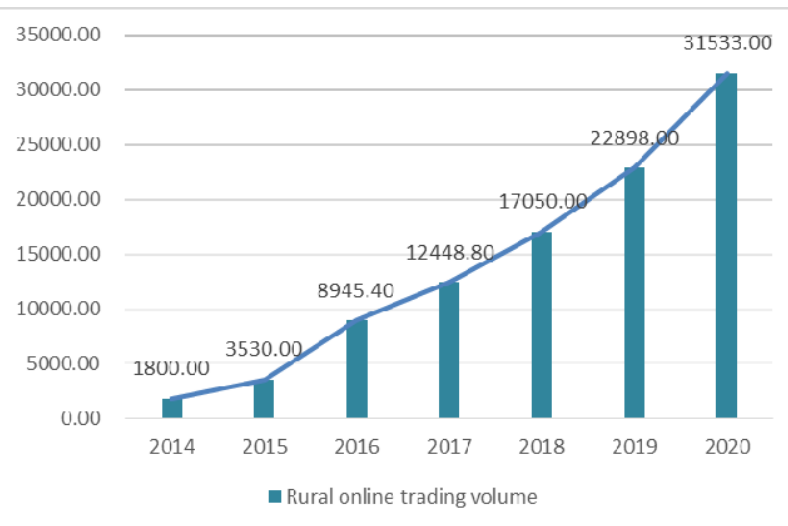

Fig. 1. Rural online trading volume of China from 2014 to 2020

With the continuous improvement of rural network, logistics and other infrastructures, e-commerce has achieved obvious effects in driving the upward trend of agricultural products and promoting farmers' income. So far, e-commerce poverty alleviation has supported 1,180 demonstration counties and achieved full coverage of 832 national-level poverty-stricken counties across the country. In the first half of 2020 , online retail sales in national poverty-stricken counties amounted to 68.48 billion yuan, a year-on-year growth rate of $13.3 \%$, which was 8.3 percentage points higher than the growth rate of national rural online retail sales.

At the same time, multiple departments frequently issued documents requesting the promotion of the development and upgrading of agricultural e-commerce, and arranged in various fields such as talents, sales, and logistics. Recently, the Ministry of Agriculture and Rural Affairs once again issued a document requesting the cultivation of rural e-commerce entities and a complete rural industrial system. By 2025, the network sales of agricultural products will reach 1 trillion yuan, and more than 15 million innovative entrepreneurs will return to the countryside.

\subsection{Wechat business has become one of the ways for the rural government to help the poor}

In July 2019, my social practice team and I went to Ruyuan County, Shaoguan City to conduct research on rural e-commerce. In the process of visiting the countryside, according to the data provided by the local e-commerce association in Ruyuan, among the hundreds of households in Ruyuan County, approximately $70 \%$ are engaged in micro-business. Through micro-business is the way for most farmers to sell agricultural products. During the visit, through interviews with local government staff, I learned that in the measures of the local government's precision poverty alleviation plan, there are also examples of helping farmers sell agricultural products through micro-business.

\subsection{Rural inclusive finance will become a new "blue ocean" for third-party payment companies}

The "Analysis Report on China's Inclusive Financial Indicators (2019)" released by the People's Bank of China in October 2020 shows that the penetration rate of electronic payment continues to increase, and the urbanrural gap has narrowed. The survey shows that the proportion of adults using electronic payments nationwide is $85.37 \%, 2.98$ percentage points higher than the previous year; the proportion of adults using electronic payments in rural areas is 76.21\%, 4.06 percentage points higher than the previous year. The mobile payment business continued to grow rapidly, and the online payment business of non-bank payment institutions showed the characteristics of a large number of transactions and a small average amount.

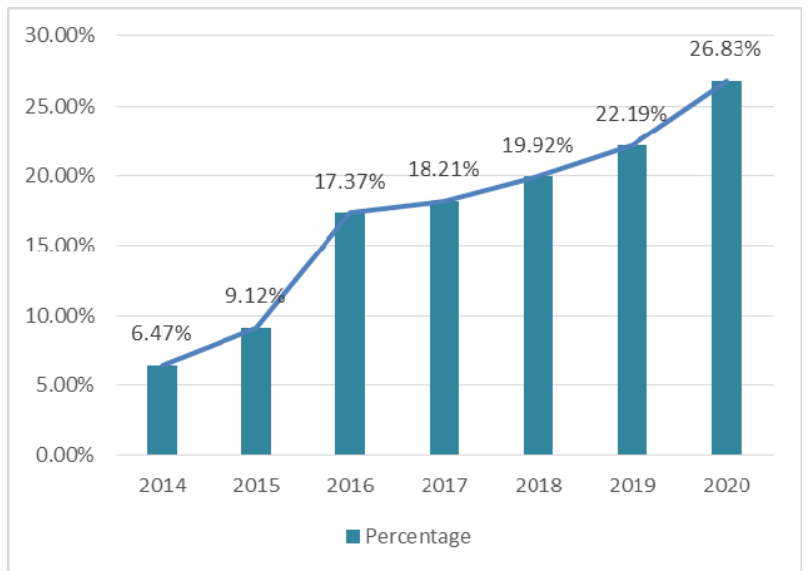

Fig. 2. Proportion of rural trading in online trading in China

With the development of emerging technologies, the rapid growth of rural income has brought about the rapid development of mobile payment demand. In 2018, mobile payments in rural areas in China reached 274.883 billion with an amount of 74.42 trillion yuan, an increase of $112.25 \%$ and $73.48 \%$ respectively, accounting for $94.85 \%$ and $96.66 \%$ of online payments, respectively. 


\section{3 the main problems faced by China's digital economy poverty alleviation villages}

\subsection{Farmers are weak in using digital economy to get rid of poverty}

The cultural level of rural residents is generally low, the living environment and thinking mode are relatively fixed, and they habitually avoid the impact of new things. The digital economy awareness urgently needs to enhance. The basic prerequisite for rural e-commerce to help farmers rid of poverty and become rich is that farmers themselves have a strong initiative to get rid of poverty. They can actively change their thinking mode under the promotion of e-commerce in the new era, are willing to understand e-commerce, and are willing to participate in local rural organizations. Various rural ecommerce publicity activities and professional training.

However, in the actual development of rural ecommerce poverty alleviation work, there are still the following problems: First, some farmers enjoy long-term state financial subsidies for the poor, and rely on subsidies to meet their daily needs, and they have a weak awareness of taking the initiative to get rid of poverty. Second, farmers have less knowledge of e-commerce and are not aware of the advantages of e-commerce in promoting agricultural product sales, which leads to negative responses and poor coordination.

\subsection{The degree of branding and standardization of agricultural products is low}

Brand, as far as consumers are concerned, is the guarantee of product quality and service. At the same time, the brand adds economic value to the product's own value. This is reflected in the fact that an excellent product brand is not only favored and recognized by consumers, enhances market competitiveness, but also helps to increase the market value of the product, thereby expanding its profit margin.

Some poverty-stricken areas blindly learn about ecommerce poverty alleviation, invest a lot of capital in ecommerce poverty alleviation, lack market research, and cannot make overall planning. This is not only detrimental to the brand building of agricultural products, but also greatly affects the income of farmers.

In poverty-stricken areas, agricultural products are mainly produced by traditional peasant households. The production of agricultural products is cyclical. The quality of the products grown in different seasons and places is different, resulting in uneven product quality. Without technical means such as production, quality inspection, packaging, transportation, and cold storage, the quality of agricultural products cannot guarantee. In general, the standardized production of agricultural products, uneven quality, and loss in transportation have affected the development of e-commerce poverty alleviation.

\subsection{The talent bottleneck of rural e-commerce needs to be broken through}

With the rapid development of e-commerce and the accelerated implementation of e-commerce projects in rural areas, the gap in e-commerce professionals with high standards has continued to widen, and digital technology professionals continue to be scarce.

There are a large number of rural Internet users in China, but very few farmers master e-commerce. In the entire industry chain of poverty alleviation through ecommerce, there is a lack of professional talents in terms of agricultural product processing and management, as well as e-commerce operations, maintenance, finance, and promotion. The capacity of farmers in poverty alleviation through e-commerce is insufficient. First, the poor areas are relatively remote, and there is a serious loss of talents with higher education, and talents with skills are unwilling to return to remote areas. The leftbehind farmers are not well educated and it is difficult to conduct technical training, which seriously affects the promotion of poverty alleviation through e-commerce. Second, farmers in poor areas have weak information capture capabilities and cannot make timely adjustments to market changes.

\subsection{Rural logistics conditions are immature and transportation costs are high}

The development of e-commerce cannot do without logistics, which is an important link. Normally, ecommerce developed areas have a well-developed logistics industry, with low prices and high service quality, guaranteeing timeliness and safety while ecommerce is underdeveloped. In regions, express delivery options are few and expensive, and service quality is difficult to guarantee. On the one hand, rural ecommerce logistics requires a relatively long delivery time in rural areas. At present, big cities and towns can reach the same-day delivery or even two hours, while the current average delivery time in rural areas is more than three days. On the other hand, due to the characteristics of rural areas, rural e-commerce logistics has seasonal distribution in rural areas, which makes e-commerce logistics seasonal fluctuations. Because agricultural production is cyclical, its demand for relevant agricultural production materials also has certain cyclical differences. Coupled with the seasonal growth cycle of agricultural products, the upward trend of agricultural products is also seasonal.

Restricted by the construction of infrastructure and the transformation of network equipment, it is currently not possible to access the modern payment and settlement system in some rural areas. Existing electronic payment systems are inadequate, and rural financial payment and settlement methods are relatively simple, focusing on cash services and bank transfers, while mobile payments, especially some new mobile payment methods based on biometric technologies, are rare. There are few types of payment and settlement tools, and the utilization rate of self-service equipment such as online banking, mobile banking, and mobile POS is not high. 
The rural financial payment and settlement environment still needs to be further improved.

\section{Countermeasures and Paths for China's Digital Economy to Help the Poor Villages}

\subsection{Increase the promotion and popularization of rural e-commerce}

In view of the current farmers' weak awareness of using e-commerce to get rid of poverty, it is necessary to find the root causes of rural farmers' ignorance and unacceptability of e-commerce, and explain to farmers in appropriate ways, for example, through village broadcasts and slogans. , Chanting, etc. to carry out preaching, we can also give full play to the village leaders.

\subsection{Promote the standardization of agricultural production}

The creation of characteristic agricultural products requires brand support, and the government, enterprises, and brand planning. Construction and operation of poor areas must promote. Establish a brand image, be guided by market demand, highlight the quality and connotation of agricultural products, strengthen quality supervision and management in the production process, inject the ecological environment, natural scenery, ethnic characteristics, and human geography of poor areas into products, and then integrate e-commerce platforms Resources, cooperate with Alibaba, JD, Suning and other companies to create unique brands. At the same time, relying on big data, improve the supply and demand information network of agricultural products, improve the dynamic monitoring of rural agricultural products, and understand market information and changes in time through big data analysis to achieve real-time feedback

\subsection{Strengthen the training of rural e-commerce talents}

The report of the 19th National Congress of the Communist Party of China stated that to implement the strategy of rural revitalization, it is necessary to cultivate a "three rural" work force that understands agriculture, loves the countryside, and loves farmers. Talent revitalization is the key to rural revitalization.

First, local governments should try to establish cooperation channels with well-known e-commerce platforms, local outstanding agricultural product ecommerce related enterprises, and local agricultural colleges or colleges with e-commerce majors to explore a rural e-commerce talent training system with local characteristics. We can try to establish a rural ecommerce talent database, follow-up training of more potential talents, and focus on and support the various stages of talent growth. Second, carry out various types of e-commerce training programs in rural areas, and provide more opportunities for people who are interested in returning to their hometowns to start their own businesses and local farmers to expand their Internet thinking and learn e-commerce expertise.

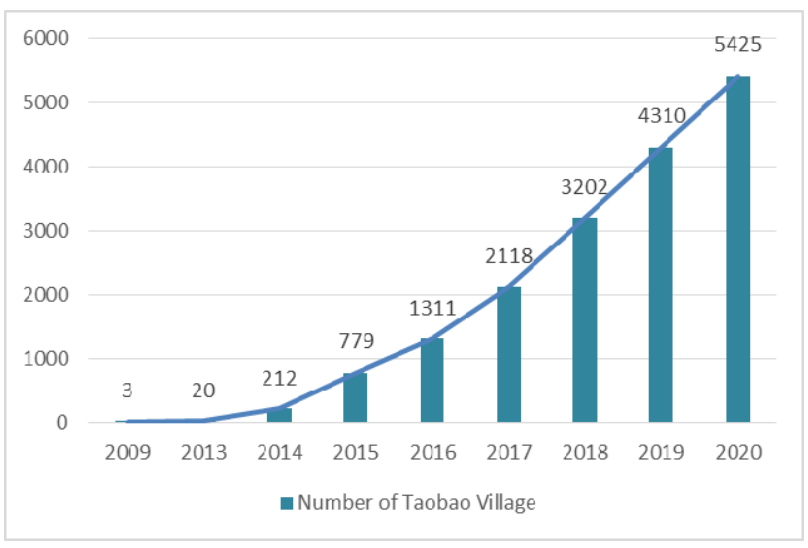

Fig. 3. Number of Taobao Village in China

\subsection{Speed up the construction of a complete logistics system}

The government should use the market and policies flexibly to accelerate the integration of county logistics resources encourage and guide rural e-commerce logistics to undertake by one or two enterprises, increase the concentration of logistics distribution, and accelerate the speed of logistics distribution. Express companies should focus on high-efficiency transportation and smooth the two-way circulation channels for the delivery of agricultural products and the delivery of agricultural tools to the countryside. With the logistics-sorting center as the hub and the local rural service station as the radiation radius, the service last mile should place to realize county, High-efficiency operation of the threelevel logistics distribution system of township and village.

\subsection{Increasing innovation in payment and settlement services}

Promote non-cash payment tools suitable for rural areas. The development of the payment system in rural areas should "adjust measures to local conditions and pay attention to people's livelihood". The promotion of noncash payment tools in rural areas must be in payment areas that related to farmers' production and life and have urgent needs. Seek a breakthrough in variety. In terms of service targets, according to the transaction characteristics of growers, breeders, processing households and self-employed households, innovate noncash payment tools suitable for the economic characteristics of rural areas, such as bankcards, telephone payment terminals, etc., without seeking big and complete. At the same time, vigorously develop new non-cash payment tools such as online banking, mobile banking, and telephone banking, and increase breakthroughs and innovations in financial services such as small deposits and withdrawals in rural areas.

On the one hand, it creates a powerful payment and settlement environment for the development of rural e- 
commerce. Strengthen the management of payment platforms, unblock rural e-commerce payment channels, innovate payment tools and settlement methods, build a high-efficiency payment and settlement network, support multiple business products, multiple channels, and multiple service objects, and improve the pertinence of payment and settlement. At the same time, extensive cooperation with third-party payment institutions to share payment settlement systems.

\section{Summary and Outlook}

The prosperity of the country leads to the prosperity of the country, and the decline of the country leads to the decline of the country. If the city compared to a big tree, then the country is its root system. The 19th National Congress of the Communist Party of China pointed out that the issue of agricultural and rural farmers is a fundamental issue related to the national economy and the people's livelihood, and that solving the "three rural" issues must always be the top priority of the whole party. For a long time, the party and the state have paid great attention to the development of rural economy, and through the introduction of a series of related policies to help rural areas overcome poverty and rejuvenate. At this stage, the digital economy provides new opportunities for rural development, effectively combining "Internet +" with the rural revitalization strategy, and accelerating the conversion of new and old kinetic energy in rural areas, so as to achieve the effect of " $1+1>2$ ".

First, the digital economy can promote the transformation of rural economic efficiency. For a long time, agricultural products have mostly relied on the farmer's market to solve channel problems. However, with the emergence of new e-commerce such as Pinduoduo, people have a "24-hour market" that is not restricted by time and region.

Second, the digital economy can promote the quality transformation of rural industries. This depends on advancing the digital transformation of agriculture, including accelerating the promotion of cloud computing, big data, Internet of Things, and artificial intelligence in the application of agricultural production and management, and promoting a new generation of information technology and the comprehensive depth of planting, seed industry, animal husbandry, and fishery. Integration of applications will accelerate the integration of primary, secondary and tertiary industries and allow farmers to share the value-added benefits of the entire industry chain.

Finally, the digital economy can promote the popularization of rural mobile payments. The fundamental way out for rural areas lies in innovation. The government should vigorously encourage financial institutions to develop and promote payment products and services that fit farmers' lives and meet the characteristics of rural areas based on serving the "three rural" and rural economic needs.

Year 2020 is the final year for China to fight decisively against poverty and build a well-off society in an all-round way. In order to enter a well-off society in an all-round way, rural revitalization requires digital development. With such big opportunities as "digital economy" and "Internet + rural areas", we cannot ignore the huge challenges it brings us. Not only to see the presentation of beautiful data, but also to analyze and judge the situation in detail based on the specific situation, take the initiative to intervene around the difficulties, pain points, and blocking points, plan early, do a good job of risk control, so that the digital economy can better serve the revitalization of the countryside strategy. It is convinced that under the joint efforts of the government, platforms, enterprises, and farmers, the digital economy will surely release a stronger and more precise driving force for rural revitalization.

\section{Acknowledgments}

This research was funded by Research Program of Guangzhou Social Sciences in 2021 (2021GZGJ50), Study on Stabilizing and Optimizing the Supply Chain and Industrial Chain: Supply Chain of Perishable Products with Multi-age Structure as an Example; and Innovation Center for China-US Youth Exchange Program, Guangdong University of Finance and Economics.

\section{References}

1. S. Heng, Y. Xu, Research on rural e-commerce poverty alleviation under the background of rural revitalization strategy, Electronic Commerce, 2(2020).

2. J. Zhang, Research on the promotion path of noncash payment tools in rural areas, Chinese Market, 43(2014).

3. D. Ma, Research on the countermeasures of rural ecommerce in helping poverty alleviation, Rural Economy and Technology, 31(2020).

4. Q. Cao. Empower rural revitalization with digital economy, Jiaxing Daily, 1(2020).

5. J. Wang. The historical evolution and future prospects of rural payment methods in the new era. Journal of the Party School of the Taiyuan Municipal Committee of the Communist Party of China, 4(2020). 